Citation: Greco, G. M. \& Jankowska, A. (2019). Framing media accessibility quality. Journal of Audiovisual Translation, 2(2), 1-10.

Copyright: (C2019 Greco \& Jankowska. This is an open access article distributed under the terms of the Creative Commons Attribution License. This allows for unrestricted use, distribution, and reproduction in any medium, provided the original author and source are credited.

\section{Framing Media Accessibility Quality}

\section{Dian Maria Greco ${ }^{\varpi}$}

Autonomous University of Barcelona, Spain

University of Vigo, Spain

(D) Anna Jankowska

Jagiellonian University in Kraków, Poland

\begin{abstract}
The article provides an initial general overview of the status of quality in media accessibility. After highlighting some of the reasons behind the importance of addressing quality in media accessibility, the article discusses some problems that undermine the potential for full maturation of research and practices on quality. Then, it presents some possible solutions and proposes to use "media accessibility quality" to refer to the overarching problem of quality in media accessibility. The article concludes by listing a set of actions that constitutes a first draft of an agenda for the future of media accessibility quality.
\end{abstract}

Key words: accessibility studies, audiovisual translation, media accessibility, media accessibility quality, quality. 


\section{Introduction}

Quality is one of the first topics collectively identified as a major issue in the field of translation studies. The official recognition of quality as a critical issue by the international translation community can be traced back to at least the third congress of the International Federation of Translators held in 1959, under the heading, "quality in translation". In the book's preface, summarising the preparatory discussions that led to the choice of the topic, Caille (1963b) states:

After weighing the pros and cons for a long time, we fixed our choice on the theme of quality. The word opened such horizons that it lost its clarity. We knew it. However, it was right in the centre of the imperatives of the profession. It was a bit of a geometric locus in abstracto - and had the merit of provoking the immediate reaction of translators as well as those who needed them. The term 'quality' was also the richest in extensions. It required the study of the entire mechanism of the profession, it involved looking into the training of translators, information, documentation, the exchanges of translators between countries, delivery times for a work, defending copyright, the remuneration for translated works, etc. (p. xiv)

If we look at the articles included in the over 550-page proceedings, we can identify many of the questions that are still under debate nowadays from the subjectivity of translation quality to the strive for the identification of objective measures, from fidelity to adaptation, from the impact of limited time and low pay on the work of professionals - and thus on the quality of the work to non-professionalism (Cary \& Jumpelt, 1963). Since then, quality has become one of the most hotlydiscussed issues in translation studies, as testified by the massive number of monographs, edited books, journals' special issues, articles, and conferences. A simple search on Google Scholar for "translation quality" gives 38.700 results. ${ }^{1}$ Obviously, this search does not have any substantial bibliometric value, and thus does not accurately represent the status of the literature on the topic. It would need to be refined with more precision; for example, by excluding the publications where the search string occurs but that are not relevant while including those that discuss the topic but do not use that string. Still, the figure gives us a sense of just how significant a topic quality is in translation studies. Its prominent status has been reinforced by the advent of the information revolution, and it is now taking on a new life with the increase in technological developments, such as artificial intelligence, whose widespread adoption may trigger radical changes in our world.

Reaching a similar outlook is much more difficult for audiovisual translation (AVT) and media accessibility (MA). When searching for "quality + 'audiovisual translation"” and "quality + 'media accessibility'", Google Scholar retrieves 4.720 and 1.960 entries, respectively. ${ }^{2}$ Once more, the results are by no means representative of the situation and should be refined. A direct comparison with translation studies would also not be fair, given that MA and AVT are new

\footnotetext{
${ }^{1}$ Retrieved December 27, 2019.

${ }^{2}$ Retrieved December 27, 2019.
} 
additions to the knowledge enterprise club. Nonetheless, given the low number of results, at least a bit more insight can be gained for the case of MA, being the one with the lowest number of entries and thus easier to analyse. Almost half of the entries $(n=928)$ refer to works produced in the past five years (2015-2019), and only the $6 \%$ of them $(n=58)$ are not relevant. We can see that of late, the topic of quality has become of increased significance among scholars. One more sign of the intensifying interest is the UMAQ conference held in Barcelona in June 2018, the first one ever explicitly devoted to quality in MA. It attracted so much interest that a second edition has been already scheduled to be held at the University of Vigo in September 2020.

This special issue of the Journal of Audiovisual Translation marks the first collective publication that deals specifically with quality in MA and AVT. Some of the articles included in this special issue discuss the topic of quality only marginally. The choice is not accidental. They accurately represent the breadth and complexity of the issue of quality as well as the current fragmented status of the debate, which we will further delve into in the following pages. With this special issue, the Journal of Audiovisual Translation has created a new section called Practice Reports. Once again, the choice is not accidental. Despite the complexity involved in specifying what constitutes quality, a multitude of MA actors - such as practitioners, companies, service providers, and users - deal with the issue of quality on a daily basis (Pedersen, 2017). Some of them have developed their own procedures, methods, models, and metrics, which are continuously tested and modified and are thus of great use in helping address quality.

Since the specific contribution of each article is clearly summarised in its own abstract, we will dedicate the following pages to a brief discussion of several of the general issues at hand. More specifically, in section two we will highlight the importance of addressing quality in MA. In section three, we will discuss some problems that undermine the potential for full maturation of research and practices on quality in $M A$, and we will discuss some possible solutions. Finally, in section four we conclude with a list some actions that constitute a first draft of an agenda for future research.

\section{The Importance of Quality in Media Accessibility}

Initially born, at least academically, as an area of AVT, MA has been steadily growing into an area of accessibility studies, becoming a driver for major social change. As proposed by Greco (2018), a prominent reason behind this process can be identified in the three shifts that MA has been experiencing over the past few years: a shift from particularist accounts to a universalist account of accessibility, from maker-centred to user-centred approaches, and from reactive to proactive models. Firstly, for many years MA was framed as the subdomain of AVT concerned with specific modalities related to persons with sensory disabilities. More recently, scholars have been increasingly embracing a universalist account that challenges traditional notions of AVT and MA, and sees MA as the area of accessibility studies that focuses on "access to media and non-media 
objects, services and environments through media solutions, for any person who cannot or would not be able to, either partially or completely, access them in their original form" (Greco, 2019, p. 18). Secondly, though previously ignored or downplayed for years, the involvement of users has become a bedrock of MA. Users are now seen as bearers of unique knowledge that is essential for both the design and the evaluation of access solutions. And lastly, while MA solutions have long been regarded as an add-on and, as such, relegated to the end of the production process of an artefact, they are now at the centre of practices that promote their full integration into that very process, jumping from the ex-post to the ex-ante phase.

The change of focus from quantity to quality can be seen as connected to and influenced by the new position reached by $\mathrm{MA}$ as a consequence of the aforementioned shifts. For quite some time, research and industry have focused on the development and implementation of access services, while policies have focused on promoting the widespread adoption of those services and setting quotas (Romero-Fresco, 2016). However, over the past few years, the different actors, especially scholars, have increasingly started to turn their attention to the quality of those services, through the development of quality models (e.g., Pedersen, 2017; Romero-Fresco \& Pérez, 2015; Romero-Fresco \& Pöchhacker, 2018), the analysis of quality in production practices (e.g., Robert \& Remael, 2016), and the discussion of the impact of machine translation on the quality of access services (e.g., Doherty \& Kruger, 2018), just to name a few cases. As stated above, the rise of quality as a major concern can be connected to the three major shifts MA has been experiencing over the past few years. A case in point is the shift from maker-centred and expert-centred to user-centred approaches, which is evident in the recent increase of reception studies within MA (Di Giovanni \& Gambier, 2018; Jankowska, 2019). In order to investigate the quality of MA services and products, identify critical issues, devise solution-oriented strategies, and define and test quality metrics, researchers have been conducting more and more tests with end-users using methods from other research fields, such as experimental psychology.

Given the situation briefly summarised so far, two questions stand out. What are the factors driving the move towards quality? And, why should quality matter in MA? A detailed answer to these questions would require more space than the one at our disposal. For the scope of this article, it is sufficient to draft some possible answers. As for the first question, let us sketch only some of the many factors that are guiding the rise in prominence of quality in MA. One factor is the recent change of pace in international, especially European, policies, with the publication of documents that either directly address or indirectly affect MA. Just consider the new Audio Visual Media Services Directive ${ }^{3}$ and the European Accessibility Act ${ }^{4}$. A second factor is the growing relevance of standards and their very practical influence on the daily life of individuals. Consider the increasing involvement of MA researchers in the work of standardisation organisations (Matamala \& Orero, 2018) and the recent

\footnotetext{
${ }^{3}$ https://ec.europa.eu/digital-single-market/en/revision-audiovisual-media-services-directive-avmsd

${ }^{4}$ https://ec.europa.eu/social/main.jsp?catld=1202
} 
release of a series of standards on accessibility, such the standard on "Accessibility requirements for ICT products and services" 5 and one on "Design for All" 6 . A third factor can be identified in the social transformations brought about by information and communication technologies. They are radically changing the patterns of access to the world and making MA services more and more necessary instruments for guaranteeing access for all (Graham \& Dutton, 2014; Greco, 2018). Finally, the second and third shifts mentioned previously have also significantly contributed to making quality a priority. For example, the search for ways to increase the quality of experience offered by MA services is strictly connected with the inquiry into the integration of those services in the production process (Fryer, 2018; Romero-Fresco, 2019).

In order to answer the second question however, we should look more closely at the first shift in MA, or better still, at its general standing. The shift from particularist accounts to a universalist account of MA mirrors and is a consequence of a more general shift concerning accessibility within the human rights framework. It is precisely in this shift that we can identify the core reason behind the importance of the topic of quality in MA. The most commonly accepted justification for human rights is that they are instruments for human dignity. In order to guarantee human rights, and thus human dignity, we need to provide access to the various material and immaterial goods that are the objects of human rights, that is, that are considered to be fundamental for a dignified life. This means that access is a necessary requirement for the fulfilment of human rights and the respect of human dignity (Greco, 2016). However, merely providing access services - i.e., quantity - is not sufficient. In a hypothetical world where access services are so widespread to pervade every aspect of life, human rights and human dignity could still be at risk if those access services do not provide an equitable experience to all. It is precisely in the experiential dimension that the importance of quality lies.

\section{Quality in Media Accessibility: Some Problems}

Despite an ever more dynamic situation, research on quality in MA is facing the risk to be undermined by a series of foundational and methodological problems that may hamper its growth to a mature stage. Openly addressing these problems should be a priority for scholars as well as for other stakeholders. If not tackled through a collective commitment in a timely manner, they may very well jeopardise the successful implementation of research results into practice, and ultimately run the risk of reinforcing old - or even producing new - inequalities.

\footnotetext{
${ }^{5}$ https://standards.cen.eu/dyn/www/f?p=204:110:0::.::FSP PROJECT,FSP ORG ID:66602,855949\&cs=1EDAD 9D32175767F919BCC673EA996CFD

${ }^{6}$ https://standards.cen.eu/dyn/www/f?p=204:110:0::::FSP PROJECT,FSP ORG ID:62323,2301962\&cs=1D28 CFDC66E7CEF3CE441294CAA9FEABE
} 
The most pressing problem is that of fragmentation. So far, attention has been spread out over a very diverse range of issues while lacking a cohesive framework for the investigation of quality in MA. To be clear, there is nothing wrong with focusing on minute aspects of a wider problem and trying to solve them. Actually, it could be quite a commendable strategy, if only put into the right structure. The Cartesian method of dividing a problem into smaller parts presupposes the existence of such a problem to divide. Without being contextualised in relation to a bigger problem, all the efforts put into addressing the small issues may risk being done in vain, or to have minimal effect, or to be even counter-productive. Until now, scholars have limited their efforts to address quality to only some modalities or contexts, and often exclusively on specific aspects of these. The general problem of what quality is in MA has been largely ignored. Actually, even the smaller problem of what quality is for those modalities or in those contexts has not been extensively addressed; and research has usually focused on some specific dimensions of quality for those modalities.

However, posing the overarching problem of quality in MA - as well as posing the general problem of quality for each MA service - and being aware of its complexities and implications is crucial for having a cohesive framework that could then support a solid inquiry into the small issues. Having such a unified framework for the investigation of quality in MA does not entail that all efforts should be focused on the formulation of a unified theory of quality in MA. Quality is an inherently vague term. Any attempt to formulate a unified theory of quality would be pointless or even detrimental, even in the case of a single MA service. However, a common framework would facilitate the correlation between the different aspects involved as well as encourage a harmonised discussion on quality in MA. It could also act as an ideal place where researchers might be able to coordinate their efforts in order to provide a more efficient and interconnected account of the various issues connected to quality.

A second problem is related to the relationship between MA and translation studies. In the context of MA, this means that a good portion of the research carried out so far is still too strictly based on, or even mirror with minimal adaptation, models and metrics from translation studies. More generally, research in MA still addresses the problem of quality adopting a translation-based and translation-centred approach. From a historical point of view, this is comprehensible. Academically, MA was born as a subfield of AVT, and thus of translation studies. The significant influence of translation studies should therefore not surprise. However, this view considers access problems as merely a case of a more general class of translation problems. As discussed in Greco (2019), this is rather controversial and could lead to a series of abuses and misuses of both translation and accessibility. AVT and MA do not overlap, but rather, intersect. This means that quality issues in MA cannot be reduced to AVT quality issues. The latter do not satisfactory cover the problem of access, which on the contrary is the ultimate question in MA. Consider audio description. So far research on quality has focused on the most diverse aspects of a film as an audiovisual text, that is, it has approached audio description from a translation-based and translation-centred approach. Nontranslation-based aspects, such as delivery (e.g., choice of voice, pace, and intonation) and reproduction (e.g., sound mix) 
have been deemed as secondary or even ignored. In MA, where the aim is to provide access to an equitable experience, these aspects are not secondary at all. The new position of MA as an area of accessibility studies, that only intersects with translation studies, requires us to start looking at the issue of quality from other points of view beyond translation (Greco, 2019; Greco \& Jankowska, in press).

A third problem concerns the nature of quality. Despite its vagueness, or more properly as a way to deal with it, there is a widespread agreement to interpret quality as a multidimensional construct. According to this view, quality is a function of different variables, i.e., its dimensions. The multidimensionality of quality has received scarce attention in MA. Thus far, research has focused on one or a few dimensions of quality for some specific MA service, such as accuracy, segmentation, or synchronisation. As we said, such a focus on small problems is a commendable enterprise from a Cartesian point of view. However, if not explicitly clarified that the one under scrutiny is part of a set of dimensions, there is the risk of conducting research on some dimension of an MA service but then drawing conclusions at the general level of quality for that service. Such a risk is also faced by some of the various models produced so far for evaluating quality in the context of some MA service, which merely mention other dimensions. Consequently, they are not models for the evaluation of quality per se, but only for the evaluation of some dimensions. Nonetheless, they are often perceived as being models about (overall) quality, as a consequence of the classic synecdochal move of confusing a part for the whole. Moreover, the dimensions ignored or minimised are often the ones that do not involve forms of translation, which take us back to the problem of the dominion of translation-centred approached to quality in MA.

A fourth problem is, prima facie, terminological. It concerns the lack of a specific noun for indicating the general topic of quality in the context of MA. Something similar to translation quality in the field of translation studies. We suggest to use media accessibility quality (MAQ). While seeming like a trivial issue, it is far from that; and it is not a mere terminological issue either. It connects especially with both the influence of translation-based approaches and the fragmentation of efforts. Adopting MAQ to refer to the general problem of quality in MA would help to keep present that whatever the specific topic at hand, it is part of a wider context. For example, in a paper that presents the research results on some dimension of quality in subtitling, just mentioning MAQ would prompt the readers to recall the general context within which they should frame both the research and its results. Starting to refer to MAQ may also facilitate a more systematic approach to the issue of quality in media accessibility, encouraging more coordinated efforts in research and practices. Most importantly, it would act as a reminder that, whatever the specific issue addressed at a certain point might be, it should be matched upon the problem of access, that is, the ultimate question of MA. 


\section{Conclusion: A First Draft of an Agenda for Media Accessibility Quality}

Given the picture drawn in the previous pages, in this concluding section we will briefly suggest a series of lines of action that await MAQ in the course of time, and that we believe would benefit from a more systematic and coordinated discussion as per the terms discussed in the previous pages. Some of the actions mirror the problems analysed in the previous section. As in that case, the following list should not be considered exhaustive either. Our main goal is to raise awareness and encourage further work.

A first action concerns the very concept of quality. As we mentioned, quality is inherently vague. This is not ignored in MA. Yet, it should be acknowledged even more explicitly. Acknowledging - and reminding more often - the vague nature of quality could, for example, save us from falling into the trap of considering some model as the model.

A second action concerns the fact that dealing with quality means navigating the treacherous waters between the Scylla of objectivity and the Charybdis of relativity. This is an issue already extensively debated in other fields but only marginally in MA. It would mean, for example, trying to justify the choice of some specific dimensions. Is that choice completely arbitrary? Is it possible to find some mechanism that could confer some forms of objectivity?

This point leads to a third action: dealing with the lack of proper acknowledgement of the agency distribution involved in the definition of both quality and models for its evaluation in specific MA services. This means, for example, investigating the role of the human factor in the definition and assessment of quality, dealing with the differences among stakeholders, defining mechanisms for addressing the divergent perspective and expectations of the various stakeholders, and, especially, providing a justification for such choices.

A fourth action concerns the need make quality models and research results user-friendly (RomeroFresco, in press). That is, finding ways to $(a)$ make research results and models understandable by the different stakeholders, especially users; and $(b)$ improve how we communicate research results to and how we engage with the other stakeholders. So far this has been done sporadically. We need to make it a regular activity.

A fifth action is to investigate the usefulness of adopting the distinction between quality of service and quality of experience, following the example of other fields.

A sixth action concerns the systematic extension of research on quality to all the different end users' groups - such as children, younger adults, the elderly, migrants - and not only to persons with disabilities. This means that future investigation on quality should also address the role played by intersectionality in both the definition and the assessment of quality in MA. 
A seventh action is related to the pedagogy of MA (Greco, in press). More attention should be paid to $(a)$ the investigation of the influence of current education and training programmes on how the question of quality is framed in MA, and $(b)$ how the issue of quality should be presented and discussed in education and training curricula. An eight action involves looking at how quality has been addressed in other fields. The development in time of new, ad hoc approaches, and thus methods and metrics, that respond to the specificities of MA is not a remote possibility, though one that would require substantial efforts. However, in line with the interdisciplinary nature of accessibility studies and thus of MA, a more practicable path would be to look at the theories, methods, and metrics produced in other fields that face the problem of quality and investigate if and how they can be applied, upon due modification, to the context of MAQ.

In his opening speech delivered at the congress of the International Federation of Translators we mentioned in the introductory section, Caillé (1963a) states: "in a world where translation is increasingly used, quality is a basic necessity and our touchstone" (p. 8). Paraphrasing his words, we believe that in a world where accessibility is increasingly becoming and used as an essential tool for human dignity, quality is indeed a basic necessity and should be the touchstone of all research and practices in accessibility studies, including MA.

\section{Acknowledgements}

We express our gratitude to the authors and the reviewers for their contributions to this special issue. Gian Maria Greco is the first author of this article. Teressa Canosa skilfully copyedited the final version. The research presented in this article as well as this special issue have received funding from the European Union's Horizon 2020 research and innovation programme under the Marie Skłodowska-Curie grant agreement No 752659 and Mobility Plus Grant no 1311/MOB/IV/2015/0 of the Polish Ministry of Science and Higher Education for the years 2016-2019. Gian Maria Greco is a member of the TransMedia Catalonia research group, funded by the Catalan government under the SGR funding scheme (2017SGR113), and the GALMA research group, funded by the Galician government under the scheme Proxecto de Excelencia 2017.

\section{References}

Caillé, P.-F. (1963a). Discours inaugural. In E. Cary \& R. W. Jumpelt (Eds.), Quality in translation. Proceedings of the IIIrd congress of the International Federation of Translators (FIT), Bad Godesberg Germany, 1959 (pp. 5-10). Oxford: Pergamon Press.

Caillé, P.-F. (1963b). Préface. In E. Cary \& R. W. Jumpelt (Eds.), Quality in translation. Proceedings of the IIIrd congress of the International Federation of Translators (FIT), Bad Godesberg Germany, 1959 (pp. v-xviii). Oxford: Pergamon Press. 
Cary, E., \& Jumpelt, R. W. (Eds.). (1963). Quality in translation. Proceedings of the IIIrd congress of the International Federation of Translators (FIT), Bad Godesberg Germany, 1959. Oxford: Pergamon Press.

Di Giovanni, E., \& Gambier, Y. (2018). Introduction. In E. Di Giovanni \& Y. Gambier (Eds.), Reception Studies and Audiovisual Translation (pp. VII-XII). Amsterdam: John Benjamins.

Doherty, S., \& Kruger, J.-L. (2018). Assessing quality in human-and machine-generated subtitles and captions. In J. Moorkens, S. Castilho, F. Gaspari, \& S. Doherty (Eds.), Translation quality assessment (pp. 179-197). Cham, Switzerland: Springer.

Fryer, L. (2018). Staging the audio describer: An exploration of integrated audio description. Disability Studies quarterly, 38(3).

Graham, M., \& Dutton, W. H. (2014). Society and the Internet. How networks of information and communication are changing our lives. Oxford: Oxford University Press.

Greco, G. M. (2016). On accessibility as a human right, with an application to media accessibility. In A. Matamala \& P. Orero (Eds.), Researching audio description. New approaches (pp. 11-33). London: Palgrave Macmillan.

Greco, G. M. (2018). The nature of accessibility studies. Journal of Audiovisual Translation, 1(1), 205-232.

Greco, G. M. (2019). Accessibility studies: Abuses, misuses and the method of poietic design. In C. Stephanidis (Ed.), HCIl 2019 (pp. 15-27). Cham: Springer.

Greco, G. M. (in press). Towards a pedagogy of accessibility. The need for critical learning spaces in media accessibility education and training. Linguistica Antverpiensia, 18.

Greco, G. M., \& Jankowska, A. (in press). Media accessibility within and beyond audiovisual translation. In Ł. Bogucki \& M. Deckert (Eds.), The Palgrave handbook of audiovisual translation and media accessibility. Cham: Palgrave Macmillan.

Jankowska, A. (2019). Audiovisual media accessibility. In E. Angelone, M. Ehrensberger-Dow, \& G. Massey (Eds.), The Bloomsbury companion to language industry studies (pp. 231-259). London: Bloomsbury Academic Publishing.

Matamala, A., \& Orero, P. (2018). Standardising accessibility: transferring knowledge to society. Journal of Audiovisual Translation, 1(1), 139-154.

Pedersen, J. (2017). The FAR model: Assessing quality in interlingual subtitling. Journal of Specialised Translation(28), 210-229.

Robert, I., \& Remael, A. (2016). Quality control in the subtitling industry: an exploratory survey study. Meta: Journal des traducteurs/Meta: Translators' Journal, 61(3), 578-605.

Romero-Fresco, P. (2016). Accessing communication: The quality of live subtitles in the UK. Language \& Communication, 49, 56-69.

Romero-Fresco, P. (2019). Accessible filmmaking: Integrating translation and accessibility into the filmmaking process. London: Routledge.

Romero-Fresco, P. (in press). Negotiating quality assessment in media accessibility: The case of live subtitling. Universal access in the information society.

Romero-Fresco, P., \& Pérez, J. M. (2015). Accuracy rate in live subtitling: The NER model. In R. Baños Piñero \& J. Díaz Cintas (Eds.), Audiovisual translation in a global context (pp. 2850). London: Palgrave Macmillan.

Romero-Fresco, P., \& Pöchhacker, F. (2018). Quality assessment in interlingual live subtitling: The NTR Model. Linguistica Antverpiensia, New Series-Themes in Translation Studies, 16, 149-167. 